Para citar esta reseña / To cite this review:

BELTRAN, Vicenç (2022), «Reseña de Historia de la poesía medieval castellana. Tomo I. La trama de las materias"», Revista de Cancioneros Impresos y Manuscritos, 11, pp. 322-328. https://doi.org/10.14198/rcim.2022.11.09

\title{
RESEÑA DE HISTORIA DE LA POESÍA MEDIEVAL CASTELLANA. TOMO I. LA TRAMA DE LAS MATERIAS REVIEW OF HISTORIA DE LA POESÍA MEDIEVAL CASTELLANA. TOMO I. LA TRAMA DE LAS MATERIAS
}

\section{Vicenç Beltran}

Accademia Nazionale dei Lincei-Institut d'Estudis Catalans-Universitat de Barcelona, Spain vicent.beltran@ub.edu

https://orcid.org/0000-0002-6598-7972

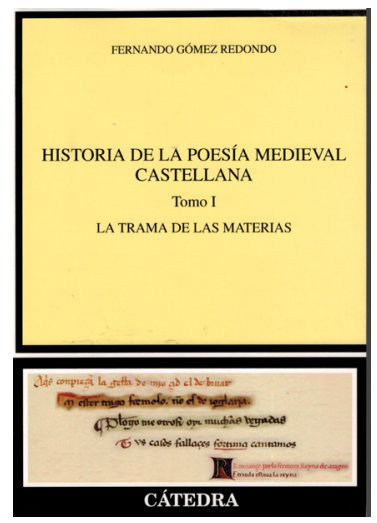

Fernando Gómez Redondo, Historia de la poesía medieval castellana. Tomo I. La trama de las materias, Madrid, Cátedra, 2020, 1349 pp. ISBN: 978-84-376-4186-7.

PALABRAS CLAVE: poesía; cancionero; romancero; tópicos; historiografía KEYWORDS: poetry; songbook; ballads; topics; historiography

Después de los magníficos seis tomos dedicados a la prosa medieval y del período de los Reyes Católicos (que no representan sino lo más conocido de su extensa y rigurosa producción), sería ocioso plantearse la capacidad de Fernando Gómez Redondo para sacar adelante un proyecto como el que este volumen aborda. Conocida es también su habilidad para trazar excelentes e innovadores marcos teóricos a los que ajusta incansablemente el análisis de las obras a lo largo de miles de páginas, sin olvidar jamás 
el marco y sin salirse de él, pero también sin que le permita pasar por alto ninguno de los mil y un detalles con que cada gran obra literaria nos sorprende a cada página. Este es el punto de partida (p. 10) de la nueva obra que ahora nos ocupa, explícitamente incrementado con nuevos parámetros en los que integra visiblemente (pp. 11-14) la experiencia adquirida en la Historia de la métrica medieval castellana (coordinada por este autor en colaboración con C. Alvar, V. Beltran y E. González-Blanco García, San Millán de la Cogolla, CiLengua, 2016). Por fin una larga introducción al contexto expecífico de la poesía medieval (las tradiciones castellana, provenzal, aragonesa, gallego-portuguesa, portuguesa e italiana) y a los elementos religiosos, culturales, políticos, ideológicos y linajísticos que la sustentan (casi una monografía) da paso al estudio de la épica.

Sería imposible en una recensión, aunque alcanzara la longitud de un gran artículo, reseñar todos los aspectos destacables de una obra tan extensa, por lo que me limitaré a algunos puntos significativos de su método y de sus logros. La materia época está organizada como es tradicional por ciclos, aunque se puede destacar la interpretación genealógica de los Infantes de Salas o la firme articulación de la materia carolingia en el discurso historiográfico castellano; es terreno movedizo, agitado por teorías contrapuestas más apoyadas a veces en presupuestos metodológicos y hasta en posturas más ideológicas y nacionalistas que filológicas, entre cuyos meandros el autor se mueve con buen juicio, adoptando las interpretaciones más consolidadas (la tradicionalista de las noticias cronísticas sobre los pares carolingios, pp. 217-223) o dejando la interpretación en suspenso cuando los materiales aportados por cada escuela no parecen imponerse por sí mismos (pp. 282-283).

El llamado mester de clerecía es desestimado como taxonomía de los textos pues «no sirve la dicotomía tradicional que enfrenta un mester de juglaría con otro de clerecía [...] resulta más efectivo confrontar artes de versificación y "poesía" en cuanto dimensiones referidas a la totalidad de los elementos que intervienen en la articulación pragmática de las obras en verso» (p. 26); en consecuencia, el capítulo III 
(«Materia de la Antigüedad») se abre con un detallado análisis de sus presupuestos métrico-prosódicos, eruditos y sociales y de las características de su recepción, basados en la compilación de informaciones dispersas en numerosos tratados poéticos o en prosa, a veces muy lejanos de esta escuela por su cronología o su trasfondo cultural. Este replanteamiento ha llevado a la inserción de la otrora aislada Historia troyana polimétrica junto a las historias antiguas (Alexandre y Apolonio) y a separarla de la «Materia hagiográfica y adoctrinamiento litúrgico» (cap. IV), etiqueta bajo la que encierra la producción de Berceo; a tenor de su trasfondo erudito y su ámbito de recepción, logra incluir en este apartado los que suelen conocerse como poemas juglarescos de tema religioso, así como las aljamiadas Coplas de Yuçuf y de Yoçef. Lo mismo cabe decir de la "Materia doctrinal: disputas y catecismos religiosos» (cap. V), en el que se incluyen desde la Disputa del alma y el cuerpo hasta la Dança de la muerte, sin olvidar tampoco los dos poemas de tradición rabínica hallados en las Huelgas de Burgos. "Material sapiencial: catecismos éticos» (cap. VI) es la etiqueta bajo la que reúne materiales a primera vista heterogéneos, distribuidos a lo largo de dos siglos: el Catón, los Proverbios de Sem Tob, el Rimado de Palacio y las Virtudes y vicios de Fernán Pérez de Guzmán.

La reunión de materiales que, desde el punto de vista de la tradición crítica, pueden resultar heterogéneos queda además justificada desde el punto de vista de la sociedad ibérica medieval, en la que convivían tres religiones y sus etnias, desgraciadamente con menos armonía de la que algunos historiadores suelen proponer. Nos hallamos ante capítulos (sobre todo el III y el IV) caracterizados por una tradición crítica no tan antigua pero muy consolidada (¿quién se acuerda ya de aquel Berceo, clérigo crédulo e ignorante cuya ingenuidad ponderaban los estudios de no hace tanto tiempo?) donde, aparte de los estados de la cuestión, objeto central de una historia de la literatura, interesan también por su capacidad de síntesis y de organización y por la propuesta de nuevas claves interpretativas. 
Otro capítulo de no fácil ordenación es el relativo a la «materia historiográfica», que asocia obras en verso relativas a episodios históricos muy heterogéneos desde iAy Jerusalén!, pasando por la Conmemoración breve de los reyes de Portugal, hasta la Consolatoria de Juan Barba y el Panegírico a la reina doña Isabel de Diego Guillén de Ávila. El hilo conductor es en este caso un «rastro de textos que permite comprender la sustitución de los cantares de gesta por poemas de factura culta, capaces de dar acogida al amplio trazado de compilaciones cronísticas - de diferentes modalidades [...]-, sostenidas por soluciones prosódicas muy variadas y por combinaciones de diferentes coplas» que se van escalonando desde "poemas noticieros», pasando por la «utilización de la historia para formular doctrinales políticos para educar a un joven príncipe o para apoyar los derechos sucesorios» (p. 717), hasta el «análisis de los textos historiográficos concebidos como panegíricos» (p. 718), un recorrido que lleva desde los orígenes hasta Historia partenopea en torno al Gran Capitán. Estos capítulos incluyen materiales muy heterogéneos cuyas características confluyentes, aunque a veces parezca que crujen las junturas, permiten al autor la elaboración de complejos cuadros de conjunto.

El capítulo octavo incluye "composiciones y tratados en los que se discuta y reflexione sobre los asuntos y las controversias que agitan la vida pública, buscando consolidar las posiciones ideológicas de las diferentes figuras que se ven involucradas en estas continuas contiendas» (p. 828); cuando el lector descubre que está hablando de obras como el Laberinto de Fortuna o la Comedieta de Ponça queda de manifiesto el cambio copernicano de perspectiva a que se ven sometidas estas obras pues, si bien en la producción de las últimas décadas se ha tendido cada vez con mayor intensidad a fijarlas en su contexto histórico y a atribuirles intencionalidad política, esta deja de ser la conclusión del análisis de algunas obras concretas para erigirse en el eje interpretativo de una amplísima panoplia que suele llenar las páginas de las historias literarias sin sacarlas nunca del reduccionista criterio de la literariedad. Poco importa en este contexto que este apartado primero aparezca bajo el discutible epígrafe de 
«épica alegórica»; en los siguientes desfilarán los «Regimientos de príncipes», los "Tratados genealógicos», los «Panegíricos» y las elegías dedicadas a los mayores protagonistas del siglo, tan dejadas de lado hasta ayer mismo como la de Diego del Castillo para Alfonso el Magnánimo, tan ignoradas como las que se dedicaron a Fernando el Católico, cuya recuperación está en curso lo mismo, o tan desconocidas como el recién reencontrado Laborinto del duque de Cádiz. Notable es también la atención que dedica en varios de estos apartados a figuras antaño tan olvidadas como Pedro de Gracia Dei. Las cuatro sátiras del siglo ocupan el resto de capítulo, dando paso al noveno que se dedica a un tipo de material normalmente alejado a las historias de la literatura: son los tratados de formación profesional en verso, entre los que sobresalen los de tipo médico cuya vulgarización (en su doble sentido: 'difusión' y 'traducción al vulgar') se generalizó en toda Europa desde la peste negra.

El capítulo final del libro va dedicado alúltimo de los géneros que emergieron en la Edad Media, el romancero. Sin desechar ninguna de las aportaciones del tradicionalismo ni de los estudios del romancero oral, antes asumiendo sus conclusiones; siguiendo las actuales líneas de investigación, su estudio avanza anclado en el momento de su emergencia textual desde la versión de La dama y el pastor copiada en el cartapacio de Jaume d'Olesa hasta el fin del período que se ha propuesto estudiar, el hito de 1520 fijado Brian Dutton en su Repertorio. La exposición procede según la cronología y los romances se agrupan según fuentes de transmisión, dedicando la misma atención a los tradicionales épicos que a los juglarescos o a los trovadorescos, elementos todos de una cadena que trata de interpretar; sintomático de este proceder es la agrupación del Romance del Conde Alarcos y del Romance de Calisto y Melibea bajo la común etiqueta "materia sentimental», siendo tan disímiles en su contenido, estilo, origen y objetivos, pero agrupados «acorde con las expectativas de recepción de finales del siglo XV» (p. 1210); sintomático es también que ante la duda de si el primero dio pie a «Retraída estaba la reina» de Carvajal (como no dudaría en afirmar el tradicionalismo clásico) zanje que «la relación también pudo ser la contraria» (pp. 1210 y 1211). De ahí 
la conclusión de que «el romancero que se conserva es básicamente culto, compuesto por autores cortesanos para un público que sabría apreciar tanto los poemas de nuevo cuño como las glosas o los contrahacimientos de unos temas o materias, que a su vez se habrían difundido por medio de otros discursos textuales [...]. Los romances se cantaban, luego se musicaban, pero también se glosaban y se leían; estos variados procesos de difusión posibilitan la creación de un discurso narrativo que es capaz de mantener el imaginario heroico y caballeresco de la Edad Medid, así como el cortesano de la poesía cancioneril, para ponerlo al servicio de los nuevos grupos de recepción de los siglos XVI y XVII» (p. 1229).

El libro que nos ocupa escapa, como decía al principio, de las posibilidades de un juicio simple y conjunto; cada parte puede ser tomada como una monografía, a lo que contribuye no poco la falta de unas páginas conclusivas que no se pueden juzgar innecesarias por la transferencia de su contenido a los capítulos metodológicos iniciales. Sin embargo, es loable que poemas muy estudiados presenten un tratamiento equivalente, cuando no equiparable, a otros que esperaban todavía la mano que supiera tocarlos; no es que se menosprecie la tradición erudita, reseñada con notable cuidado, sino que se busca para cada obra un análisis completo y suficiente, basado en el texto, donde las aportaciones precedentes quedan integradas en la argumentación. No creo sin embargo que hubiese resultado inútil dedicar a cada capítulo un apartado de conclusiones, que solo se ha considerado necesaria en último, el romancero, quizá por la novedad del enfoque.

El tratamiento de los diversos capítulos está condicionado por la desigualdad de su tradición crítica: la épica y el romancero poseen un corpus de estudios cuya abundancia puede sobrecoger pero cuyas conclusiones pueden verse mediatizadas por las discusiones entre escuelas; el mester de clerecía se beneficia hoy de una notable coincidencia en sus métodos y premisas culturales; la lírica bajomedieval ha entrado más recientemente en el canon de los estudiosos y no ha acabado de imponerse en la comunidad científica la imagen coherente que las numerosas 
aportaciones de las últimas cuatro décadas han construido con perseverancia. Por último, el autor no ha desestimado ninguna de las producciones en verso, aunque estén tan desnudas de análisis literario como los tratados de medicina. Una obra de conjunto no puede sino resentirse de estas diferencias en el tratamiento de sus partes y la necesidad de encuadrar cada sector de la producción medieval en verso, cuyos parámetros raramente coinciden con los de la moderna, ha obligado a forzar los límites de los capítulos en forma inusitada en otros períodos literarios. A pesar de estos desafíos hemos de valorar positivamente cada una de sus partes pues el autor ha ido adaptando sus criterios y su metodología a condiciones diversas cuyos resultados no podían ser homogéneos. Aunque podamos estar en desacuerdo con algunas de las decisiones adoptadas o con el tratamiento de alguno de los sectores, la mano del autor ha impuesto su sello y el juicio no puede partir sino de la dificultad de la empresa y de la coherencia de los resultados.

Pasando ya a los aspectos editoriales, el autor, contra lo que había hecho en las dos partes de la Historia de la prosa, ha cerrado este primer volumen con un detallado índice general que, por sí mismo, se puede considerar un prontuario para quien busque información sobre cualquier problema concreto. Podemos encontrar lunares, inevitables en una obra de tal envergadura, pero como sus antecedentes, por la línea innovadora en que se inserta y por la profundidad y extensión de las materias que aborda, así como por la comodidad con que cada lector podrá encontrar allí un punto de partida para su formación o para sus investigaciones, marcará un antes y un después en el desarrollo de los estudios sobre poesía medieval. 